\title{
Overweight Status in Indian Children: Prevalence and Psychosocial Correlates
}

\author{
*Nicolle Fernandes, Jagdish Khubchandani, Denise Seabert, and \#Swateja Nimkar \\ From Department of Physiology and Health Science, Ball State University, Indiana; *Dietetic Technician Program, LaGuardia \\ Community College, New York; and \#Department of Education, Health Services Program, University of Southern Indiana, \\ Indiana; USA.
}

Correspondence to:

Dr Jagdish Khubchandani,

Department of Physiology and Health

Science, Ball State University,

Indiana, USA.

Jkhubchandan@bsu.edu

Received: June 10, 2014;

Initial review: September 22, 2014;

Accepted: November 07, 2014.

\begin{abstract}
Objective: To examine the association between overweight status and psycho-social risk factors in Indian children. Methods: Data from India's nationally-representative Global School-based Student Health Survey were analyzed using SPSS for all participating students ( $n=8130,58 \%$ males). Results: The likelihood of being overweight was significantly higher for children with fewer friends $(\mathrm{OR}=1.16,95 \% \mathrm{Cl}=1.13-1.18)$ or friends who were not kind or helpful, children with symptoms of depression $(\mathrm{OR}=1.20,95 \% \mathrm{Cl}=1.03-1.39)$ and anxiety $(\mathrm{OR}=1.09,95 \% \mathrm{Cl}=1.07-1.15)$, children with little parental involvement $(\mathrm{OR}=1.06$, $95 \% \mathrm{Cl}=1.02-1.10)$, and children who felt lonely or missed school days without permission. Conclusions: Psychosocial distress in overweight Indian children warrants comprehensive interventions for screening and treatment of pediatric obesity.
\end{abstract}

Keywords: Epidemiology, Obesity, Risk factors.
$\mathrm{T}$ ill about two decades ago, the issue of overweight was emerging as a public health concern primarily in children of high-income countries and western nations [1]. However, Asian countries such as India have caught up with this phenomenon. India is now being considered a fast weightgaining nation that is, ironically, also struggling with malnutrition [2]. This paradox could be reflective of the recently emerging socio-economic trends in childhood obesity in India. According to various studies, the current prevalence of childhood overweight in India could range from $4 \%$ to $22 \%[3,4]$

Recent studies from developing countries have identified some determinants of childhood overweight [5]. Studies have also pointed toward potential connections between childhood overweight and psychosocial characteristics (e.g. depression, anxiety, and social withdrawal) [6,7]. However, the existing literature on childhood overweight and its psychosocial correlates focuses on western countries, which might not be directly relevant to India due to the differences in social, economic and cultural contexts. The purpose of this study was to explore the psychosocial correlates of childhood overweight status in India from a large national sample of children.

\section{Methods}

The Global School-based Student Health Survey (GSHS) is a 54-item questionnaire given to students in classes of 6th-11th grades in schools of India. The survey assessed students on health behaviors (e.g. hygiene, tobacco use, and mental health), social factors (e.g., peer support and family involvement), and demographic factors (e.g., age, gender, height, and weight). Students self-reported their responses to each question on a computer scannable answer sheet. More details about methods have been previously published [8].

Data from the study were analyzed using SPSS 20.0. Logistic regression analysis was used to assess the association of psychosocial factors with prevalence of overweight status in study participants.

\section{RESULTS}

A total of 8130 students completed the survey with an overall response rate of $83 \%$. Majority of the participants were males (58\%). Students from grades 8 , 9 , and 10 were almost equally represented in the final sample (range 30-36\%) (Table I). More than a quarter of students had depressive symptoms of hopelessness and sadness (26\%), missed classes or school on $\geq 1$ day during the past month (28\%), and reported that parents or guardians never/rarely checked to see if homework was done (40\%), never/rarely understood problems and worries (25\%), and never/rarely knew what students were doing with their free time (29\%). 
TABLE I CHARACTERISTICS OF THE STUDY POPULATION

\begin{tabular}{lr}
\hline Characteristics & $N(\%)$ \\
\hline Males & $4481(58)$ \\
Age & \\
$\quad \leq 13$ years old & $2664(33)$ \\
14 years old & $2654(32)$ \\
$\geq 15$ years old & $2757(34)$ \\
Grade & \\
$\quad \leq 8^{\text {th }}$ grade & $2667(33)$ \\
9 th grade & $2933(36)$ \\
$\quad \geq 10$ th grade & $2422(30)$ \\
Overweight prevalence & \\
All students & $445(8)$ \\
Males & $262(9)$ \\
Females & $183(8)$ \\
Body Mass Index & \\
All students & $18.60(0.14)$ \\
Males & $18.54(0.16)$ \\
Females & $18.68(0.19)$ \\
\hline
\end{tabular}

*Mean (Standard deviation).
On the basis of self-reported height and weight, BMI for age and gender was computed. Based on BMI, students were grouped into two categories (overweight vs normal weight). In logistic regression analyses, this variable was treated as a dependent variable to compute the odds of association with selected psychosocial factors that were treated as independent variables. Nine independent factors were found to be associated with being overweight in the study participants. Students with fewer friends, those who felt sad, hopeless, and lonely most of time (depressive symptoms), those who could not stop worrying and had sleeplessness (anxiety symptoms), students with peers who were not kind or helpful, students with little parental involvement, and those who missed classes without permission were statistically significantly more likely to be overweight Table II. A final model was created to compute adjusted odds ratios by controlling the analysis for age, gender, and grade in school. After adjustment, the number of close friends, missing school, and social support from other students in the school did not remain significant predictors of whether or not a student was overweight Table II.

TABLE II Psychosocial Risk FaCtors AsSOCIATED WITH OvERWEIGHT

\begin{tabular}{|c|c|c|}
\hline $\begin{array}{l}\text { Psychosocial Risk Factors } \\
\text { (\% prevalence in students) }\end{array}$ & $\begin{array}{c}\text { OR }(95 \% C I) \\
\text { Overweight Prevalence }\end{array}$ & $\begin{array}{c}\text { AOR }^{*}(95 \% \mathrm{CI}) \\
\text { Overweight Prevalence }\end{array}$ \\
\hline $\begin{array}{l}\text { Felt so sad or hopeless almost every day for two weeks or more } \\
\text { in a row that they stopped doing their usual activities during the } \\
\text { past } 12 \text { months ( } 26 \%)\end{array}$ & $1.23(1.06-1.43)$ & $1.20(1.03-1.39)$ \\
\hline Felt lonely most of the time or always during the past 12 months (9\%) & $1.43(1.15-1.78)$ & $1.14(1.08-1.16)$ \\
\hline $\begin{array}{l}\text { Most of the time or always felt so worried about something that they } \\
\text { could not sleep at night during the past } 12 \text { months (8\%) }\end{array}$ & $1.33(1.17-1.69)$ & $1.09(1.07-1.15)$ \\
\hline \multicolumn{3}{|l|}{ Number of close friends ${ }^{a ̂}$} \\
\hline 0 close friends $(10 \%)$ & $1.16(1.13-1.18)$ & $1.09(0.87-1.35)$ \\
\hline 1 close friend $(24 \%)$ & $1.05(1.03-1.06)$ & $1.08(0.90-1.20)$ \\
\hline 2 or more close friends (66\%) & 1(Reference) & 1(Reference) \\
\hline $\begin{array}{l}\text { Other students in the school were never or rarely kind and helpful during } \\
\text { the past month }(42 \%)^{*}\end{array}$ & $1.05(1.03-1.06)$ & $1.01(0.96-1.03)$ \\
\hline $\begin{array}{l}\text { Missed classes or school without permission on one or more days during } \\
\text { the past month (28\%)* }\end{array}$ & $1.03(1.01-1.04)$ & $1.02(0.97-1.03)$ \\
\hline $\begin{array}{l}\text { Parents or guardians never/ rarely checked to see if homework was done during } \\
\text { the past month (40\%) }\end{array}$ & $1.09(1.04-1.14)$ & $1.06(1.02-1.10)$ \\
\hline $\begin{array}{l}\text { Parents or guardians never/rarely understood problems and worries during the } \\
\text { past month }(25 \%)\end{array}$ & $1.07(1.05-1.12)$ & $1.04(1.03-1.09)$ \\
\hline $\begin{array}{l}\text { Parents or guardians never/rarely knew what students were doing with their free } \\
\text { time during the past month }(29 \%)\end{array}$ & e $1.08(1.05-1.11)$ & $1.06(1.02-1.10)$ \\
\hline
\end{tabular}




\section{What this Study Adds?}

- Evidence for high prevalence of psychosocial distress and lack of social support in Indian children who are overweight based on self-reported BMI.

\section{Discussion}

The damaging effect of being overweight on psychosocial health are undeniable. In this study sample, we report slightly higher prevalence of overweight among boys compared to girls, similar to previous studies from India [1,3,4]. The high prevalence of psychosocial distress and lack of social support reported in this study is disconcerting, due to the association of these risk factors with being overweight. Overweight children, on an average, tend to encounter lower levels of social acceptance, which can have lasting effects. For instance, the child can develop a negative body image, lower self-esteem and self-doubt that can create awkwardness in children; labeled "social insecurity". This social insecurity may result in children shunning public encounters; including but not limited to missing school days that can further impede academic progress [9-11]. Additionally, students reported unkind or nonhelping nature of fellow students and lesser involvement of parents in routine life within the past month and these factors were associated with being overweight. Previous research has indicated the presence of neglect, stigma, bias, and discrimination against overweight/obese children, which can culminate into pervasive victimization, teasing, and bullying [10-12]. Reports of depression, anxiety, and suicidal thoughts have also been associated with abnormal weight in adolescents in western countries [10-13].

The results of this study should be viewed in light of several potential limitations. First, all data were selfreported which may have led to socially desirable responses from students. Second, this was an observational study wherein cause and effect relationships could not be established. Finally, even though the study included a large sample of students across India, the results cannot be generalized to the entire population of children in India.

Adolescent overweight and obesity are multifaceted issues that need to be addressed at several levels. Parental and school involvement can facilitate and motivate the practice of healthy behaviors such as quality nutrition, routine physical activity, and assessment of behavior change [13,14]. Pediatricians should routinely screen for obesity and associated psychological problems in children and follow-up with adequate preventive and curative remedies. A multidimensional approach is needed to tackle this problem because overweight and obesity in children may induce progressive withdrawal from social life, victimization by peers, constant expectation of rejection, and low selfesteem that can make children susceptible to chronic psychiatric diseases such as anxiety, depression, and eating disorders $[14,15]$.

Acknowledgement: Dr Khubchandani is a recipient of the Diversity Associates Scholarship from the Office of Institutional Diversity at Ball State University, Indiana, USA. Contributions: NF, JK, DS, and SN: all contributed to the conception and design of the study, and the writing and critical editing of the manuscript; JK: was the chief analyst and interpreter of the data. All the authors have approved this submission.

Funding: None; Competing interests: None stated.

\section{REFERENCES}

1. Gupta N, Shah P, Nayyar S, Misra A. Childhood obesity and the metabolic syndrome in developing countries. Indian J Pediatr. 2013; 80:28-37.

2. Chatterjee P. India sees parallel rise in malnutrition and obesity. Lancet. 2002; 360:1948.

3. Vohra R, Bhardwaj P, Srivastava JP, Srivastava S, Vohra A. Overweight and obesity among school-going children of Lucknow city. J Family Community Med. 2011;18:5962.

4. Gupta DK, Shah P, Misra A, Bharadwaj S, Gulati S, Gupta N, et al. Secular trends in prevalence of overweight and obesity from 2006 to 2009 in urban Asian Indian adolescents aged 14-17 years. PLoS One. 2011;6:e17221.

5. Caballero B. The global epidemic of obesity: an overview. Epidemiol Rev. 2007; 29:1-5.

6. Vander Wal JS, Mitchell ER. Psychological complications of pediatric obesity. Pediatr Clin North Am. 2011;58:1393-401.

7. Puder JJ, Munsch S. Psychological correlates of childhood obesity. Int J Obes. 2010;34:S37-S43.

8. World Health Organization. Global school-based student health survey. Available from: http://www.who.int/chp/ gshs/en/. Accessed 25 June, 2014.

9. Hutchinson G. Tackling obesity through school-based interventions. Br J Sch Nurs. 2010;5:335-7.

10. Centers for Disease Control and Prevention. Childhood overweight and obesity, consequences. Available from: http://www.cdc.gov/obesity/childhood/consequences. html. Accessed 25 June, 2014.

11. Ben-Sefer E, Ben-Natan M, Ehrenfeld M. Childhood obesity: Current literature, policy and implications for 
practice. Int Nurs Rev. 2009;56:166-73.

12. Times of India. Taunts start at home for the obese: Study. Available from: http://timesofindia.indiatimes.com/india/ Taunts-start-at-home-for-the-obese-Study/articleshow/ 18313414.cms. Accessed 25 June, 2014.

13. Puhl RM, King KM. Weight discrimination and bullying. Best Pract Res Clin Endocrinol Metab. 2013;27:117-27.
14. Riggs N, Tewari A, Stigler M, Rodrigues L, Arora M, Khubchandani J, et al. Indian students' perspectives on obesity and school-based obesity prevention: a qualitative examination. Health Promot Pract. 2013;14:816-23.

15. Nieman P, Leblanc CM. Psychosocial aspects of child and adolescent obesity. Paediatr Child Health. 2012;17:205-8. 